\title{
Physical aspects of soil fertility - The response of roots to mechanical impedance
}

\author{
R. Scott Russell and M. J. Goss
}

ARC Letcombe Laboratory, Wantage, Oxford, England

\section{Introduction}

The title of this article may at first sight seem out of place in a publication dedicated to Professor A.C. Schuffelen as it is little related to the chemical aspects of soil fertility on which he has made such an outstanding contribution. But there are reasons for this choice. Progress in the scientific study of soil has depended largely on increasing interdisciplinary links, made possible by advancing knowledge and made necessary by emergent problems. Professor Schuffelen's work provides excellent illustrations: the rigorous and often novel application of physical chemistry to elucidating ionic equilibria between the solid and solution phases of the soil much advanced the understanding of soil/plant nutritional relationships; a decade and a half ago this knowledge enabled him, in collaboration with nuclear physicists, to encourage a logical approach to new questions posed by the deposition of worldwide fallout on the soil.

Some recent developments in agricultural practices now increasingly direct attention to another aspect of soil fertility, namely the response of root systems to their physical environment, including their reaction to mechanical stress. Here again progress will largely depend on new or strengthened interdisciplinary links. This parallel with the development of Professor Schuffelen's own interests encouraged the choice of the present subject. A further reason was the belief that the conjoint consideration of the response of plants to the chemical and physical facets of the soil environment should permit a broader understanding of the factors which control fertility.

Despite the considerable changes in agricultural practices which have occurred over the past several centuries, one basic tenet remained virtually unquestioned until the last decade, namely the importance of the careful cultivation of the soil on which arable crops are grown. Cultivation traditionally served two main functions - to produce suitable soil conditions for plant growth and to control weeds. There was no alternative method for weed control until herbicides, especially paraquat (Hood et al., $1963,1964)$, became available. Evidence that the need for cultivation can be less when weeds are absent (Russell \& Keen, 1938; Pereira, 1941) then became of practical importance, and by 1970 reduced cultivation or direct drilling (in USA 'no till') were being successfully practised in several countries. The increasing cost of labour was a particular incentive to these developments and it may be expected that the 'energy crisis' will be a further stimulus.

These new practices emphasize the importance of understanding the effects of soil physical conditions on root growth. The abandonment of annual cultivation can result in greater compaction of the soil; yet it is now evident that in many, though by no means all, situations crop yields may not be impaired. Sometimes, indeed, soil conditions appear to be better when direct drilling, as opposed to traditional cultivation, has been practised for many years (Baeumer et al., 1971). There can be no adequate basis for 
defining the conditions in which the new methods can be safely employed until the response of roots to the stresses they can experience in the modified soil conditions are more fully understood. Attention is directed to this subject also by the increasing weight of agricultural machinery which can create problems due to soil compaction, especially under wet conditions; the denser stocking of pastures, encouraged by higher herbage yields, can have the same effect (Strutt, 1970).

Knowledge of the manner in which the growth and function of roots are affected by mechanical stress when other aspects of the rooting medium are favourable provides useful background information for considering these aspects of soil fertility.

\section{Effect of mechanical stress on root growth}

The lack of attention which was given, until lately, to the manner in which plant roots respond to mechanical stress is vividly illustrated by Barley's amply justified statement in 1962 that 'the experiments of Pfeffer (1893) still provide the only detailed description of the forces which can be exerted by plant tissues'. Pfeffer had shown that when growing roots were rigidly confined by encasing them in gypsum block they were capable of exerting pressures in the range of 5-12 bar. Barley obtained broadly comparable results with more elaborate apparatus, in which growing roots were subjected to pressure with a flexible diaphragm.

However, from the viewpoint of understanding how mechanical impedance affects the exploration of the soil by roots the study of the maximum pressure which roots can exert is of lesser interest than ascertaining both the minimum applied pressures which appreciably reduce root extension and whether roots are capable of decreasing their diameter to penetrate pores which cannot be readily expanded and are of smaller cross-sectional area than the roots. The work of Wiersum (1957) provided a clear negative answer to the second question and has been supported by subsequent work (see page 307). Indeed, mechanical restraint normally causes the diameter of roots to increase. Occasional suggestions that roots do decrease in diameter to penetrate small pores are perhaps due to the fact that the mechanical restraint of root axes causes a considerable proliferation of fine laterals, provided that the pores in the medium are large enough to receive them; without careful inspection those laterals which emerge near the tip of an impeded axis can be misidentified as an extension of the axis itself.

Detailed studies of the first question - the minimum pressures which can appreciably reduce root extension - cannot be readily carried out with plants growing in soil. A major difficulty arises because increased compaction of soil is likely not only to create greater mechanical resistance to root penetration but also is often associated with altered water potential and gas exchange. The observed response of roots may thus be due to the complex interaction of these variables. Moreover, the measurement of the external pressures which roots experience in soil is subject to considerable uncertainty. Indirect procedures, for example penetrometers, must be used. Even if they are made to resemble roots in shape, three basic characteristics of the growing root cannot be simulated - the considerable capacity of its apex for deformation in response to external pressure, the ability of the root to curve round obstacles and the possible lubricating effect of the mucigel sheath which typically is developed on the root cap. Some investigators (Stolzy \& Barley, 1968; Eavis \& Payne, 1969) have attempted to compare the axial pressures roots experience when penetrating soil with those measured by penetrometers of comparable size. The pressures experienced by penetrometers can 
be appreciably greater but the fact that roots, when subjected to mechanical restraint, are often anchored to the soil by root hairs within a few millimetres of their apices makes such comparisons of doubtful significance. A further reason for regarding penetrometers as only a qualitative guide comes from work with devices equal in diameter to roots but with tips of contrasting form. Greacen et al. (1968) considered that the manner in which soil particles are displaced by penetrometers with tips similar in shape to that of a root differed considerably from the pattern of displacement shown by roots themselves. The displacement produced by root apices was judged to be more closely simulated by 'needle' penetrometers, with a $10^{\circ}$ cone at the apex - a shape markedly in contrast with that of a root. There is, however, no evidence either that these relationships hold widely for soils of different types or that the differences in the shape of the apex of penetrometers of equal diameter greatly affect the force required to insert them into soil. Prudence indicates that, at best, measurements made by penotrometers should be regarded as comparative, not absolute, guides to forces roots experience in penetrating soil.

To establish quantitative relationships between external pressure and the growth of roots there are thus strong reasons for working in artificial systems so designed that

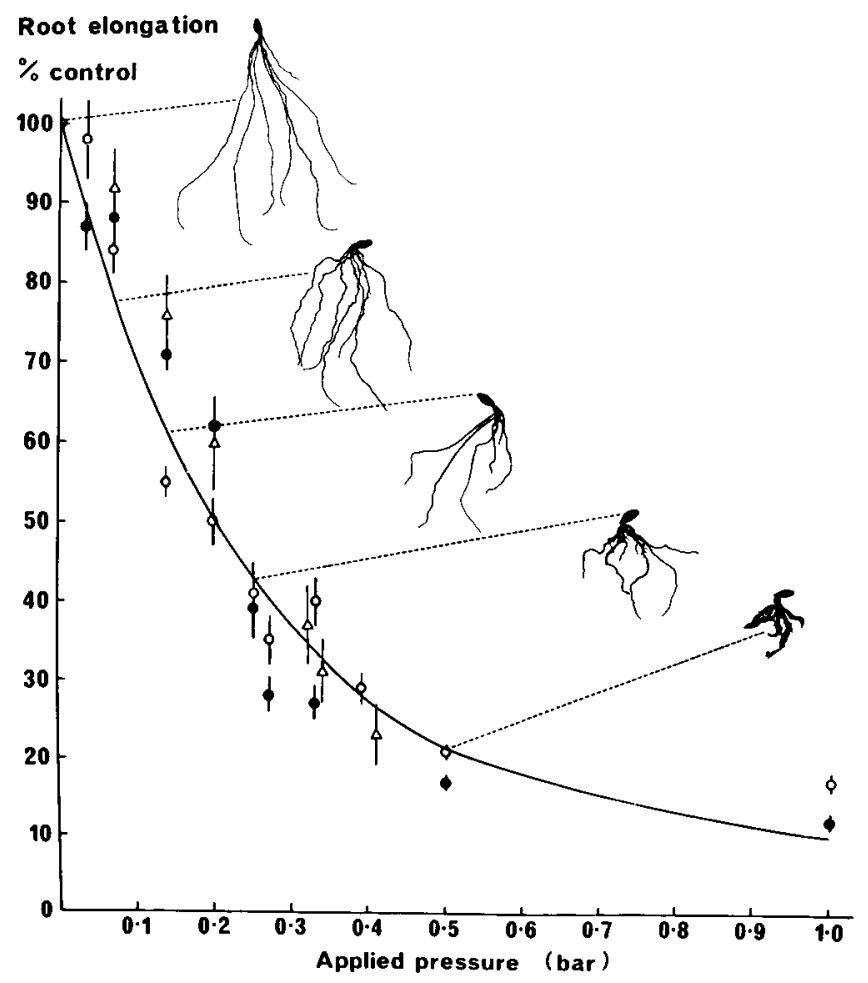

Fig. 1. Effect of applied pressure on the rate of elongation of seminal axes of barley plants grown for 6 days in beds of ballotini. Open circles: pore diameter $157 \mu \mathrm{m}$; closed circles: pore diameter $69 \mu \mathrm{m}$; triangles: pore diameter $16 \mu \mathrm{m}$. 
the external pressure roots experience can be controlled and measured accurately while all other conditions for root growth are maintained uniform and favourable. Glass spheres (ballotini) are a convenient rooting medium for this purpose. In suitably designed pliable sided containers, to which variable hydrostatic pressures are applied, the pressure which roots resist in expanding pores between the ballotini can be shown to equal the external hydrostatic pressure. The continuous circulation of aerated nutrient solution can ensure that conditions for root growth, other than external pressure, are kept constant. A detailed description of an apparatus which satisfies these requirements will be published elsewhere (Goss \& Russell, 1975). Fig. 1 shows the effect of external pressures ranging up to $1.0 \mathrm{bar}$ in the extension of the seminal axis of barley. Wide variations in the size of ballotini had no effect on the response of roots provided that the diameter of the pores between the ballotini was less than that of roots. This is of interest from two viewpoints: first it shows that the results were not an artefact due to the size of ballotini chosen; second, since the size of pore between the larger ballotini was less than that of roots by only a small factor, support is given to Wiersum's (1957) conclusion that the penetration of small pores by roots is not facilitated by them decreasing in diameter. The response to mechanical impedance shown by the curve in Fig. 1 was unaffected by the age of plants up to 21 days or by the impedance of the emerging shoots. Extension was reduced by about $50 \%$ by 0.2 bar and $80 \%$ by 0.5 bar; the following empirical equation was fitted to the results:

$$
Y=7.94+92.06 \exp -3.87 \mathrm{X}
$$

where $\mathrm{Y}$ is the rate of elongation, when the external pressure is $\mathrm{X}$ bar, expressed as a percentage of that of controls at zero pressure.

Less extensive experiments with other species showed some differences; the rate of elongation of root axes of maize was reduced to $69 \%$ of that of unimpeded plants by 0.25 bar while the corresponding figure for barley was $43 \%$. The results for wheat and sugar-beet were intermediate while peas responded similarly to maize.

The conclusion that the elongation of root axes is considerably reduced when they are subject to pressures of 0.5 bar or less is supported by the findings of other workers who have used experimental systems which provided an opportunity to attempt direct measurements of the pressures roots experience (Gill \& Miller, 1956; Barley, 1962, 1963; Abdalla et al., 1969). Abdalla et al.. alone used barley and the relationship between external pressure and root extension they described does not differ significantly from that shown in Fig. 1. In the other three investigations maize was used and in two instances (Gill \& Miller, 1956; Barley, 1962) effects were closely comparable to those for maize reported above. Somewhat contrasting findings by Barley (1963) may be due to differences in method and especially the short duration of experiments. However, in common with the other workers he found that pressures of less than 0.5 bar caused a significant reduction in root extention.

Changes in other factors in the environment can, however, modify the response of roots to mechanical stress. For example the reduction in root elongation caused by external pressure can be enhanced if the partial pressure of oxygen in the gaseous phase around the roots is reduced to 0.05 bar (Gill \& Miller, 1956; Barley, 1962).

The effect of mechanical stress on lateral roots has been studied in less detail than the response of axes but the development of both appears to be affected equally when the diameter of the pores in the medium is less than that of laterals. However, when pore diameters are intermediate between those of axes and laterals, so that the former are alone subject to mechanical stress, there is a considerable proliferation of laterals 


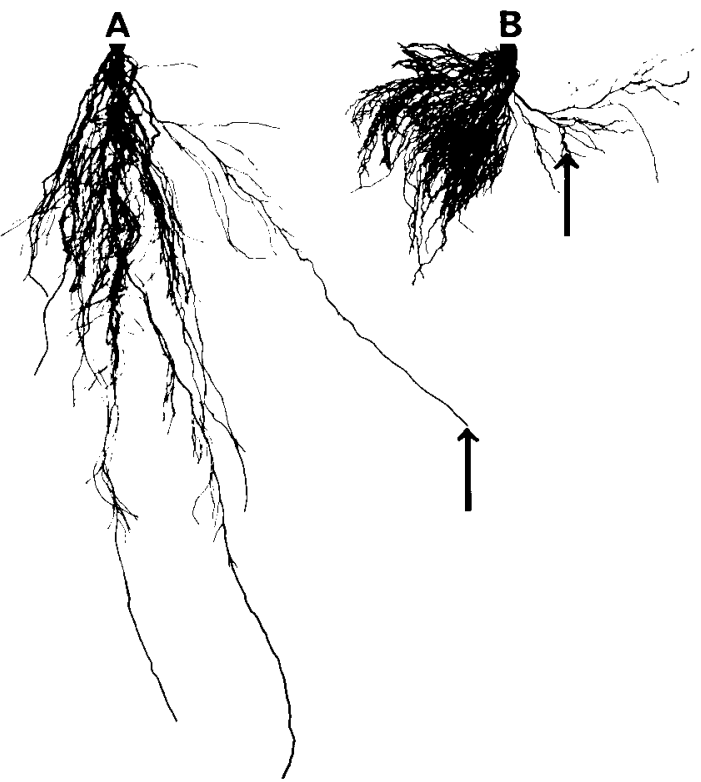

Fig. 2. Effect of mechanical impedance on the form of the root system of barley plants 21 days old grown in rigidly packed ballotini. A: axes unimpeded, pore diameter $470 \mu \mathrm{m}$; B: axes but not laterals impeded, pore diameter $157 \mu \mathrm{m}$. Impeded axes show greater branching than unimpeded.

The arrows indicate the position of the apex on one seminal axis of cach plant separated from the remainder.

(Fig. 2). These emerge much closer to the apex of the axes and constitute a much larger fraction of the whole root system (Table 1). Moreover, if the resistance offered to the elongation of axes is not uniform through the rooting zone, for example where roots enter a layer where mechanical impedance increases, laterals can proliferate particularly close to the interface. Even when the length of axes has been much reduced by impedance but there is sufficient opportunity for laterals to develop, neither the total weight of the root system nor its ability to absorb nutrients from the restricted rooting zone may be affected (Table 2). The importance of this for evaluating practical situations is obvious - an appreciable reduction in root extension caused by mechanical stress may not necessarily reduce the yield of crops.

The morphological changes caused by mechanical stress in artificial conditions are comparable to those which are found under field conditions as a result of soil com-

Table 1. Effect of mechanical impedance on the branching of seminal roots. Barley plants grown for 6 days in ballotini giving $157 \mu \mathrm{m}$ pores, with an applied pressure of 0 or 0.5 bar.

\begin{tabular}{l}
$\begin{array}{l}\text { Applied pressure } \\
\text { (bar) }\end{array}$ \\
\hline 0 \\
0.5
\end{tabular}

Seminal axes:

mean length $(\mathrm{cm})$

8.6

Laterals:

distance of youngest lateral from root apex $(\mathrm{cm})$ mean distance between primary laterals $(\mathrm{mm})$ mean length $(\mathrm{mm})$

$\begin{array}{ll}3.0 & 0.3 \\ 2.9 & 1.5 \\ 5.0 & 9.0\end{array}$


Table 2. Effect of mechanical impedance on plant growth and the uptake of potassium and phosphate by barley.

A. Potassium absorption in plants grown for 6 days with roots elongating against pressures of 0 or 0.27 bar, in beds of ballotini of sufficiently small diameter that both axes and laterals were impeded.

B. Phosphate absorption in plants grown for 21 days in rigidly packed beds of ballotini giving pores $470 \mu \mathrm{m}$ and $157 \mu \mathrm{m}$ in diameter; the latter caused root axes but not laterals to be impeded.

\begin{tabular}{lcccc}
\hline & $\begin{array}{l}\text { Length of axes } \\
\text { (\% of unimpeded) }\end{array}$ & \multicolumn{2}{l}{ Dry weight $(\mathrm{mg})$} & $\begin{array}{l}\text { Absorption } \\
(\mu \text { mol per plant) }\end{array}$ \\
\cline { 3 - 4 } & & root & shoot & \\
A. Unimpeded & 100 & 6.6 & 6.5 & 19.2 \\
Impeded & 35 & 6.4 & 6.5 & 19.5 \\
B. Unimpeded & 100 & 43 & 126 & 15.3 \\
Impeded & $3^{*}$ & 43 & 127 & 15.1 \\
\hline
\end{tabular}

* Approximate value based on depth of penetration.

A

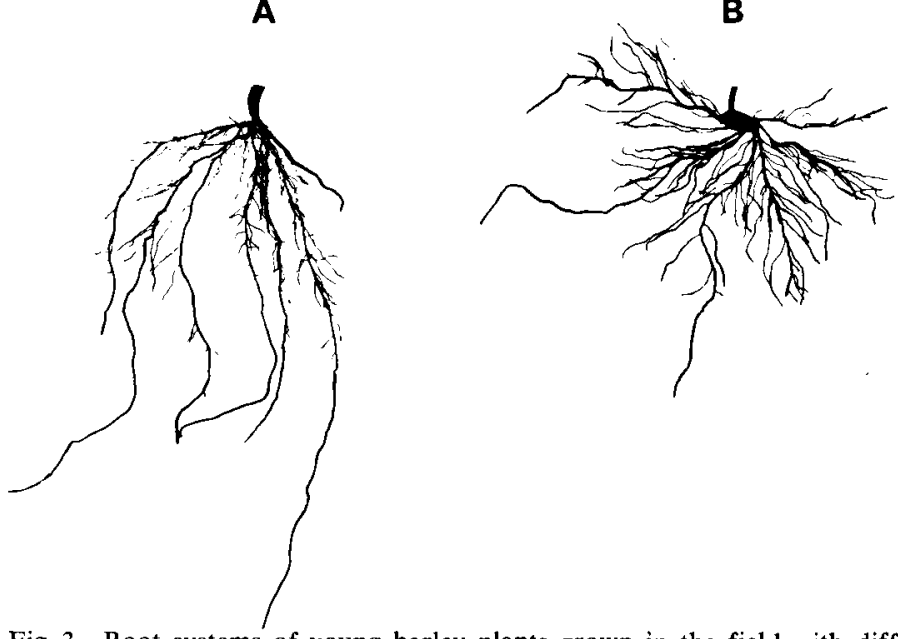

Fig. 3. Root systems of young barley plants grown in the field with different methods of cultivation. A: deep tine cultivation, bulk density of surface layer $1.35 \mathrm{~g} \mathrm{~cm}^{-3} ; \mathbf{B}$ : direct drilling, surface layer compacted to $1.50 \mathrm{~g} \mathrm{~cm}^{-3}$.

paction. Fig. 3 shows that if the compaction of soil is increased by altering the method of cultivation the length of axis is reduced and the thickness increased.

\section{The mechanism of physiological response}

Before considering the implications of the response of roots to mechanical stress in the evaluation of physical factors which influence soil fertility, it is appropriate to consider the possible nature of the operative physiological mechanisms. This can assist in identifying questions on which more information is required. 
Barley (1962) drew attention to the fact that there is ample chemical energy present in the form of readily oxidizable material in the root to meet the work expenditure needed even for rapid growth against high resistances'. He envisaged that this energy was utilized in cell extension and therefore sought to explain the response of roots in terms of osmoregulation in expanding cells. In subsequent discussions (e.g. Barley et al., 1965; Barley \& Greacen, 1967; Greacen \& Oh, 1972) the same basic approach has been adopted. Some responses to mechanical stress can be readily explained in terms of osmoregulation; the maximum pressures roots appear capable of exerting are comparable with the osmotic pressure of their expanding cells. However, many aspects of the response of roots, especially to low pressures, cannot be explained in this way. As Barley (1962) recognized, the rate of enlargement and the final volume of root cells would be smaller if their response depended on osmoregulation. However, there is evidence (Barley, 1965; Goss \& Russell, 1975) that external pressures which considerably restrict root extension do not reduce cell volume; increased cross-sectional area can counter-balance reduced cell length. Furthermore, despite Barley's statement quoted above, roots do not grow rapidly against even quite low resistance (see Fig. 1). Whereas the osmotic pressure in root cells in usually in the range $8-10$ bar, external pressures as low as 0.2 bar can halve the rate of extension.

As yet probably the most detailed attempt to explain the 'physics of root growth' in terms of osmoregulation is that of Greacen \& Oh (1972). By adjusting the water content of soil and its bulk density they prepared, from the same parent material, three series of soils with water potentials of -2.8 to -2.9 bar, -4.1 to -4.3 bar and -6.8 to -8.3 bar, respectively, each of which offered a wide range of mechanical resistance to root penetration. Because the external pressure experienced by the roots of pregerminated pea seedlings, which were grown in these soils, was inferred from penetrometer readings and not directly measured as in the work illustrated in Fig. 1, quantitative comparison of the results in that figure with those of Greacen \& $\mathrm{Oh}$ is

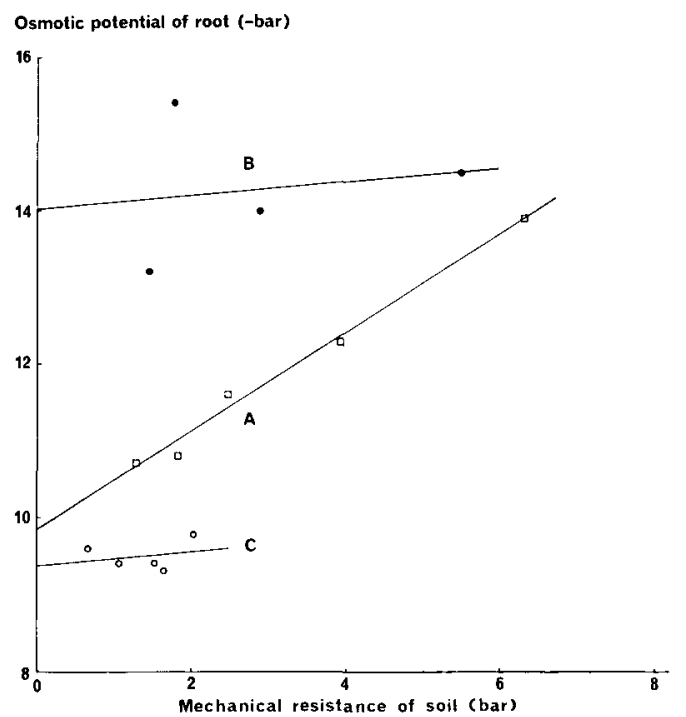

Fig. 4. Relationships between osmotic potential of pea roots and mechanical resistance of soil, estimated by Greacen \& Oh (1972). A: soil water potential about -4.2 bar (regression coefficient $0.7 \pm 0.04$ ); B: soil water potential about -7.3 bar (regression coefficient $0.09 \pm 0.35$ ); C: soil water potential about $\mathbf{- 2 . 8}$ bar (regression coefficient $0.08 \pm 0.22$ ).

(Curve A is from Greacen \& Oh (1972), Fig. 2b; Curves $B$ and $C$ have been calculated from their tabulated data.) 
impossible. It is of interest, however, that curves of a form similar to that shown in Fig. 1 also apply to the data of Greacen \& Oh (Fig. 4); points for the two higher water potentials fall on the same curve but at the lowest water potential the rate of root extension against a given external pressure is somewhat reduced.

Greacen \& Oh attributed the sensitivity of root growth to mechanical impedance to the ability of roots to osmoregulate against variable external pressure with only $70 \%$ efficiency. This conclusion rested on the slope of the line relating the estimated osmotic potential of the root tissue (based on freezing point measurements in expressed sap from living tissue) to the mechanical resistance of the soil when the soil water potential was -4.1 to -4.3 bar (Fig. 5, Line A). Their observations for soils of higher and lower potentials were not considered from this viewpoint; Lines $B$ and $C$ on Fig. 5 were therefore calculated from their tabulated data. The effect of mechanical resistance on osmotic pressure which they report at the water potential -4.2 bar was not reproduced and although the scatter of points introduces uncertainty, their method of calculation suggests that osmoregulation was considerably less at the higher and lower water potentials than at -4.2 bar. This would seem irreconcilable with the conclusion elsewhere in their paper that osmoregulation was $100 \%$ efficient at any one value for mechanical impedance over the entire range of water potentials -2.8 to -8.3 Furthermore if, firstly, their osmoregulatory hypothesis were accepted and secondly, Lines A and $\mathrm{C}$ on Fig. 5 correctly describe the relationships between mechanical resistance and osmotic potential at water potentials -2.8 and -4.2 , it would not be expected that the effect of mechanical resistance on root elongation at these two water potentials could be described by the single continuous curve shown on Fig. 4 (Line A). Thus the complete data of Greacen \& Oh do not support their hypothesis: alternative interpretations deserve consideration.

An obvious line of enquire is suggested by the considerable evidence that the extension of cell walls depends on complex metabolic processes which are under hormonal control (Cleland, 1967; Ridge \& Osborne, 1970; Davies, 1973). The involvement of growth control mechanisms in the response of roots to a number of stresses in the soil

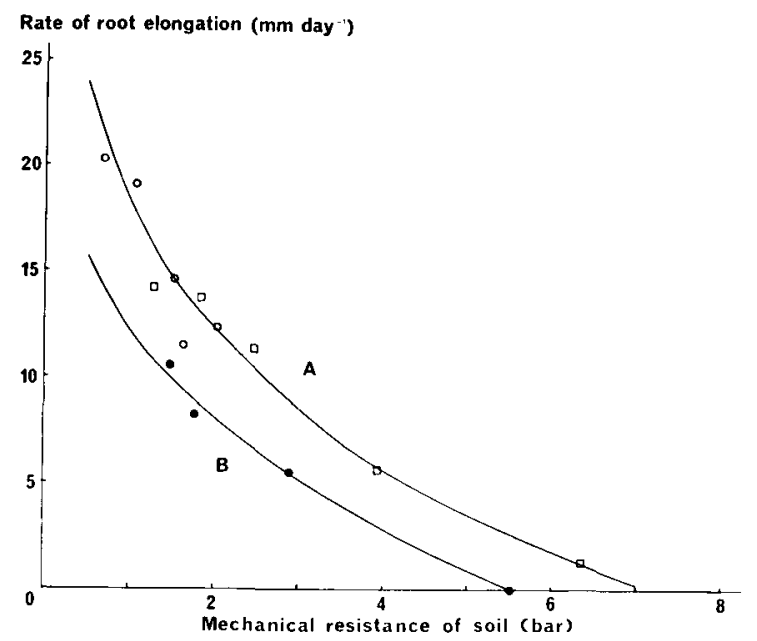

Fig. 5. Relationships between rate of elongation of pea roots ( $\mathrm{mm}$ day-1) and the mechanical resistance of the soil estimated with a needle penetrometer by Greacen \& Oh (1972). Curve A: water potential of soil about -2.8 bar (open circles) and about -4.2 bar (open squares); Curve B: water potential of soil about -7.3 bar (closed circles).

Note: Unlike Fig. 1 the external pressures roots experienced were not directly measured so that qualitative relationships shown on the two figures should not be directly compared. (Derived from tabulated data of Greacen \& Oh, 1972.) 
environment, for example anaerobiosis, salinity and water shortage, has been strongly suggested in a number of investigations (Vaadia \& Itai, 1969). Information on the effect of mechanical stress on endogenous growth substances is at present limited to indications that the evolution of ethylene can much increase when roots encounter a mechanical barrier (Kays et al., 1974) but a number of considerations suggest that a study of the effects of external pressures on growth regulatory mechanisms may be rewarding. The apical tissues of roots, including the root cap, which can be particularly subject to distortion by mechanical forces, are major sites where growth control substances are synthesized (Pratt \& Goeschl, 1969; Weiss \& Vaadia, 1965; Scott, 1972). Moreover, when roots have been grown against an external applied pressure which is subsequently relieved, their rate of extension does not return to that in unimpeded roots until 2 or 3 days later - that is to say after cells formed since the pressure was removed have reacted the stage of rapid expansion (Goss \& Russell, 1975). This 'lag' is readily compatible with the postulate that the response to mechanical impedance is initiated within the apical meristematic tissues. An observation made by Snow (1905) and recently repeated (Goss \& Drew, 1972) is again suggestive that mechanical restraint affects the growth regulatory process in roots; when root axes are forced to bend, lateral initials typically develop on the convex side (Fig. 6). Since their initiation is believed to be closely controlled by growth substances it appears likely that mechanical stress may influence the production or action of these substances.

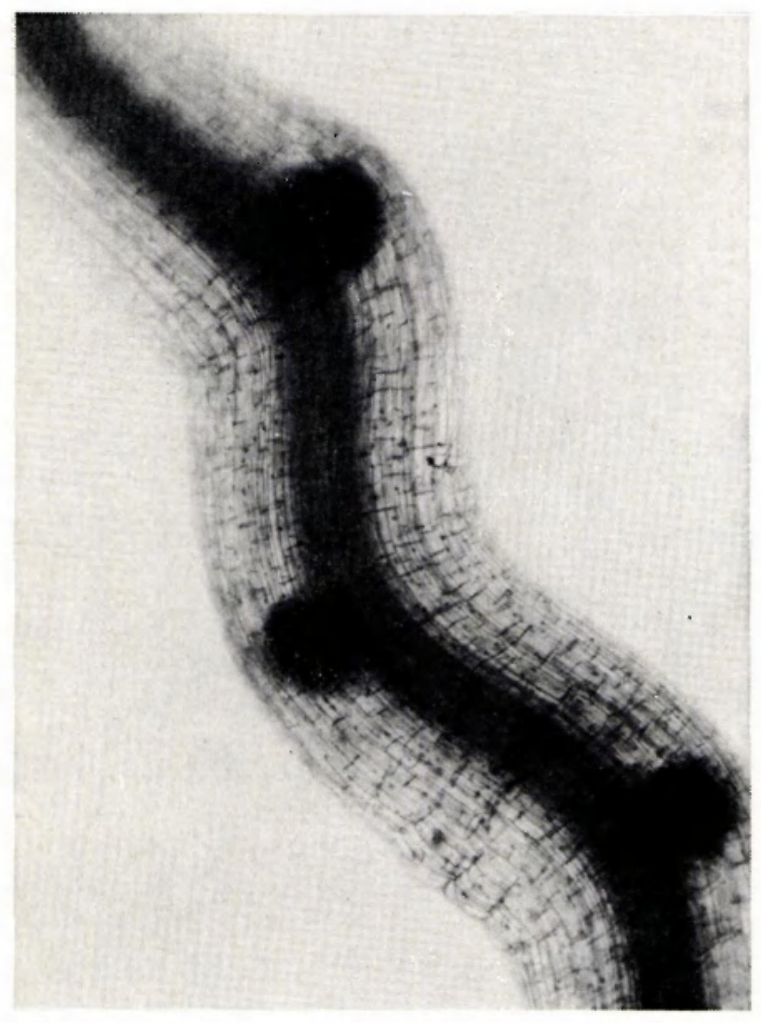

Fig. 6. Part of seminal axis of barley about $2 \mathrm{~cm}$ from apex which had been grown in ballotini $1 \mathrm{~mm}$ in diameter. Curvature of the root round ballotini causes the development of lateral meristems (dark areas in photographs) on the convex side. 
Although there has recently been much progress in the study of the production and action of endogenous growth substances, it remains one of the more difficult fields of plant physiology. Thus, it is reasonable to consider whether the search for this information should be regarded as relevant to the study of soil fertility. The fact that during the growth of the plant, and depending on the conditions experienced by roots, there can be considerable changes in the growth regulation pattern encourages an affirmative answer. If these substances mediate, at least in part, the effects on roots of mechanical impedance the response may be expected to change depending upon other aspects of the environment. Accordingly, it seems unlikely that the manner in which roots respond to mechanical stress in variable field conditions will be adequately explained until more is known of the underlying physiological mechanisms.

\section{Implications for the evaluation of soil fertility}

If the thesis advanced in the introduction to this paper is accepted it follows that the identification of situations in which mechanical stress is likely to restrict root development will in the future become increasingly important for assessing soil fertility to guide agricultural practices. What are the needs in future research? A convenient point of departure in considering this question is to contrast this problem with others which have been faced, with conspicuous success, in ameliorating soil conditions for crop growth. Nutritional amendments (with which, for present purposes, the application of calcium to adjust $\mathrm{pH}$ can be bracketed) and the application of water in irrigation serve as examples.

The value of chemical procedures for assessing nutrient requirements for crop growth is so widely recognized that it needs no emphasis. The claim that fertilizers free us completely from one natural limitation to crop production - the supply of nutrients in the soil' (Cooke, 1970) is no exaggeration, though, as Cooke emphasizes, it does not mean that we can yet do so most economically. Where inadequate water limits crop growth, the assessment of irrigation needs from meteorological factors, for example by Penman's formula (Penman, 1948) has been of comparable importance. The way in which these two advances were achieved have a negative characteristic in common - detailed study of what may be called the 'fine structure' of the root/soil system was not required. Nutrient (or lime) requirement is assessed by the analysis of the bulk soil; its hydraulic conductivity, another bulk characteristic, is the major, sometimes the only soil character of which account is usually taken in the study of water relations under field conditions. Is it realistic to imagine that the restraints which mechanical stress impose on root growth and hence on crop yields can be assessed with comparable success from those measurements of the bulk soil which it is practicable to make on a routine basis?

The dominant feature of any medium, containing a solid phase and in which other factors are favourable, which determines the ability of a root system to penetrate it freely is evident from the relationships which were discussed on p. 2-4, namely the presence of a sufficient number of continuous channels which are either at least equal in diameter to roots or which can be enlarged by them against only very low external pressures. If soil is compressed the total pore volume is reduced, particularly that occupied by pores of diameter comparable to root axes or laterals in which secondary thickening has not occurred (i.e. about $0.1-1 \mathrm{~mm}$ ) (Fig. 7). Thus an inverse relationship between bulk density and the ease with which roots penetrate any one soil is to 


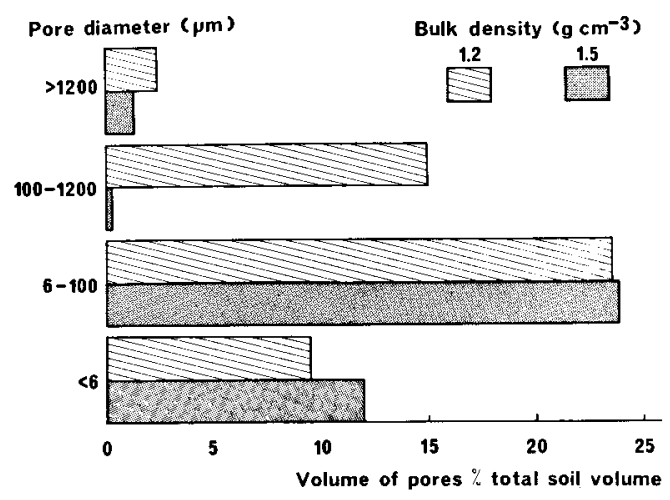

Fig. 7. Effect of compaction on pore size distribution in a sand with a $2.1 \%$ humus content.

Compaction reduced pores of diameter greater than $100 \mu \mathrm{m}$, i.e. those which young root axes or laterals could enter readily. (Derived from Schuurman, 1965.)

be expected when other factors do not supervene; this is well supported in the literature (Taylor \& Gardner, 1963); similarly as a soil is compressed, resistance to penetrometers and the restriction of root penetration can both increase in a related manner (Fig. 8). However, when different soils are compared, consistent relationships are not found - for example, whereas the limiting bulk density which permits root penetration has been estimated at 1.1 for a silty clay soil (Trouse \& Humbert, 1961), values exceeding 2.0 have been reported for a clay loam (Zimmerman \& Kardos, 1961). These variable relationships are attributable to many factors. Large differences in pore size distribution occur between soils of contrasting types. Their 'strength', which influences the forces roots must resist in enlarging pores, changes with water content. This relationship is not constant for different soils. Similarly the extent to which the air-filled pores can be reduced without creating anaerobic conditions can vary widely depending, among other factors, on the amount of oxygen consumed by the microflora.

Accordingly, although measurements of bulk density or observations with shear vanes

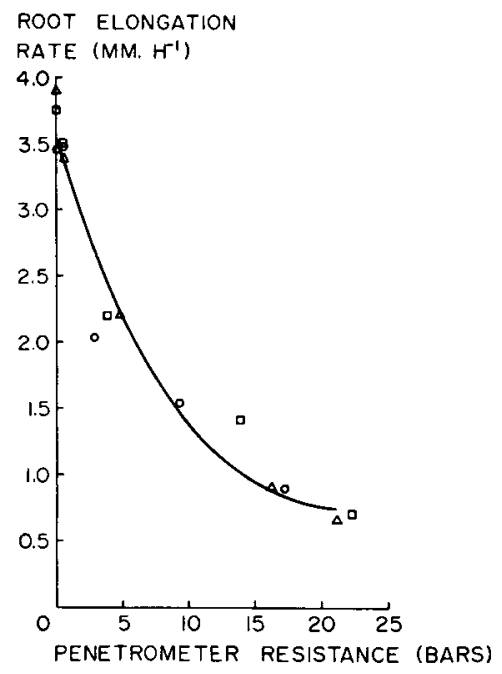

Fig. 8. Relationship between elongation of cotton roots in loamy sand and soil resistance estimated by penetrometer. Circles: soil moisture content $7.4 \%(\mathrm{w} / \mathrm{w})$; triangles: soil moisture content $5.0 \%(\mathrm{w} / \mathrm{w})$; squares: soil moisture content $4.0 \%(\mathrm{w} / \mathrm{w})$. (From Taylor \& Ratliff, 1969.) 
and field penetrometers can often provide the simplest way of detecting compacted layers caused by implements or traffic, they yields qualitative rather than quantitative information. None of these methods indicates directly the ease with which fine pores can be enlarged, or the continuity of channels which are freely accessible to plant roots. These limitations may often be or minor importance in work on soils which have been thoroughly cultivated since the fabric of the soil may then be distributed approximately at random. But the situation can be very different in relatively undisturbed soils which deserve increasing attention because of reduced cultivation or direct drilling.

When cultivation is discontinued, shrinking and swelling of the soil can lead to discontinuities between structural units; channels formed by roots can remain from one season to the next; the same is true of earthworm channels, and in some circumstances the earthworm population can increase considerably when cultivation is suspended (Schwerdtle, 1969; Cannell et al., 1973). In addition, the stability and other characteristics of the surface soil can change (Free, 1970; Baeumer \& Bakermans, 1973; Cannell \& Finney, 1973). Thus although the mean bulk density of the surface soil increases if cultivation is discontinued, a number of processes can maintain and create channels in the soil when it is not disturbed. The more rapid infiltration of water which has been observed in some untilled soils (Ehlers, 1973) is indicative of the continuity of these channels. The view that they may facilitate penetration by roots is encouraged by the finding, in some investigations, that the restriction to root extension which can occur when direct drilling is first introduced may become less or disappear when the practice is continued for several years, although the bulk density of the soil remains relatively high (Cannell et al., 1974); root performance cannot be adequately predicted from any simple soil measurement. The meagreness of present information on root structure and function in such soil environments was recently emphasized by Baeumer \& Bakermans (1973); there is at present no adequate basis for predicting how the growth of crops, which is the ultimate test of soil fertility, will be affected if reduced cultivation or direct drilling is practised for an extended period, especially in soils of low stability.

To provide this information an interdisciplinary approach is clearly needed in which account is taken equally of the physiology of root growth and function and of the physics of the soil; both its macro- and micro-structure must be considered. The problem is made more complex by interactions between compaction, water supply and aeration; they are not independent variables in the soil and all affect root growth. Reference has already been made to the influence of variations in the water content of soil on its strength and hence on its resistance to penetration by roots. Earlier discussion often stressed the importance of soil water potential in determining the ability of roots to penetrate compacted soil (Barley \& Greacen, 1967). However, the more recent findings of Greacen \& Oh (1972) (see Fig. 5) suggest that this aspect may be important only when the water potential of the soil is low.

Reduced aeration resulting from the lower air-filled pore volume in compacted soils may be potentially more important, especially when the water content of the soil is high. The manner in which anaerobic conditions affect root growth is still incompletely understood, though it is evident that injury to plants is not solely accountable to the restriction of root respiration. The production or movement of endogenous growth regulators can be affected (Reid et al., 1969), and in addition the influence of soil micro-organisms cannot be ignored. When the oxygen tension in the soil is low their toxic metabolites can accumulate, including ethylene (Smith \& Russell, 1969); moreover, the intense flora of the rhizophere competes with roots for the limited 
oxygen supply. Since the production of root exudates, which are the substrates for these organisms, appears to be enhanced when the rooting medium contains a solid phase (Barber \& Gunn, 1974) it cannot be assumed that when roots are subject to mechanical impedance their interaction with micro-organisms will be similar to that observed in simple laboratory systems. Soil micro-biology must be taken fully into account equally with soil physical and plant physiological aspects. Fortunately in the recent past there has been a considerable increase both in basic knowledge and in experimental methods which should assist in future study of these difficult questions.

In this article interactions between plant roots and the soil have been considered primarily in relation to the effects of altered methods of cultivation on soil conditions. But the types of study to which attention has been directed should also serve the wider purpose of increasing our understanding of the basic nature of the processes - chemical, physical, plant physiological and microbiological - at the root/soil interface which together control the transfer of nutrients and water from the bulk soil to plants.

\section{References}

Abdalla, A. M., D. R. P. Hettiartchi \& A. R. Reece, 1969. The mechanics of root growth in granular media. J. agric. Engng Res. 14: 236-248.

Strutt, N., 1970. Modern farming and the soil. Report of the Agricultural Advisory Council (UK). (N. Strutt, Chairman). London.

Baeumer, K. \& W. A. P. Bakermans, 1973. Zero-tillage. Adv. Agron. 25: 77-123.

Baeumer, K., W. Ehlers \& G. Pape, 1971. Erste Erfahrungen im Ackerbau ohne Bodenbearbeitung in Göttingen. Sonderh. Landw. Forsch. 26/1: 264-272.

Barber, D. A. \& K. B. Gunn, 1974. The effect of mechanical forces on the exudation of organic substances by roots of cereal plants grown under sterile conditions. New Phytol. 73: 39-45.

Barley, K. P., 1962. The effects of mechanical stress on the growth of roots. J. exp. Bot. 13: 95-110.

Barley, K. P., 1963. Influence of soil strength on growth of roots. Soil Sci. 96: 175-180.

Barley, K. P., 1965. The effect of localised pressure on the growth of the maize radicle. Aust. J. biol. Sci. 18: 499-503.

Barley, K. P., D. A. Farrell \& E. L. Greacen, 1965. The influence of soil strength on the penetration of a loam by plant roots. Aust. J. Soil Res. 3: 69-79.

Barley, K. P. \& E. L. Greacen, 1967. Mechanical resistance as a soil factor influencing the growth of roots and underground shoots. Adv. Agron. 19: 1-43.

Cannell, R. Q., F. B. Ellis, B. T. Barnes, J. G. Elliott \& F. Pollard, 1973. Effects of reduced cultivation on root development of cereals. Rep. Agric. Res. Coun. Letcombe Lab. (1972): 29-30.

Cannell, R. Q., F. B. Ellis, B. T. Barnes, K. R. Howse, R. Jackson, J. G. Elliott \& F. Pollard, 1974. Effects of reduced cultivation on soil conditions and root development of cereals. Rep. Agric. Res. Coun. Letcombe Lab. (1973): 43.

Cannell, R. Q. \& J. R. Finney, 1973. Effects of direct drilling and reduced cultivation on soil conditions for root growth. Outl. Agric. 7: 184-189.

Cleland, R., 1967. Extensibility of isolated cell walls: measurement and changes during cell elongation. Planta 74: 197-209.

Cooke, G. W., 1970. Using chemicals to increase crop productivity. In: New horizons for chemistry and industry in the 1990's. (Proc. Symp. Lancaster, 1969), p. 45-54. Society of Chemical Industry, London.

Davies, P. J., 1973. Current theories on the mode of action of auxin. Bot. Rev. 39: 139-171.

Eavis, B. W. \& D. Payne, 1969. Soil physical conditions and root growth. In: W. J. Whittington (Ed.), Root growth, p. 316-336. Butterworths, London.

Ehlers, W., 1973. Strukturzustand und zeitliche Änderung der Wasser- und Luftgehalte wahrend einer Vegetationsperiode in unbearbeiteter und bearbeiteter Löss-Parabraunerde. Z. Acker- u. PflBau 137: 213-232.

Free, G. R., 1970. Minimum tillage for corn production. Bull. Cornell Univ. agric. Exp. Stn $1030,12 \mathrm{pp}$.

Gill, W. R. \& R. D. Miller, 1956. A method for the study of the influence of mechanical impedance and aeration on the growth of seedling roots. Proc. Soil Sci. Am. 20: 154-157. 
Goss, M. J. \& M. C. Drew, 1972. Effect of mechanical impedance on growth of seedlings. Rep. Agric. Res. Coun. Letcombe Lab. (1971): 35-42.

Goss, M. J. \& R. S. Russell, 1975. In preparation.

Greacen, E. L., D. A. Farrell \& B. Cockcroft, 1968. Soil resistance to metal probes and plant roots. Trans. 9th int. Congr. Soil Sci. 1: 769-779.

Greacen, E. L. \& J. S. Oh, 1972. Physics of root growth. Nature, New Biol. 235: 24-25.

Hood, A. E. M., H. R. Jameson \& R. Cotterell, 1963. Destruction of pastures by Paraquat as a substitute for ploughing. Nature, Lond. 197: 748.

Hood, A. E. M., H. R. Jameson \& R. Cotterell, 1964. Crops grown using Paraquat as a substitute for ploughing. Nature, Lond. 201: 1070-1072.

Penman, H. L., 1948. Natural evaporation from open water, bare soil and grass. Proc. R. Soc. (A). 193: $120-145$.

Pereira, H. C., 1941. Studies on soil cultivation IX. The effect of inter-row tillage on the yield of potatoes. J. agric. Sci. 31: 212-231.

Pfeffer, W., 1893. Druck und Arbeitsleistung durch Wachsende Pflanzen. Abh. Sächs. Ges. (Akad) Wiss. 33: $235-474$.

Pratt, H. K. \& J. D. Goeschl, 1969. Physiological roles of ethylene in plants. A. Rev. Pl. Physiol. 20: 541-584.

Reid, D. M., A. Crozier \& B. M. R. Harvey, 1969. The effects of flooding on the export of gibberellins from the root to the shoot. Planta 89: 376-379.

Ridge, I. \& D. J. Osborne, 1970. Hydroxyproline and peroxidases in cell walls of Pisum sativum: regulation by ethylene. J. exp. Bot. 21: 843-856.

Russell, E. W. \& B. A. Keen, 1938. Studies on soil cultivation VII. The effect of cultivation on crop yield. J. agric. Sci. 28: 212-233.

Schuurman, J. J., 1965. Influence of soil density on root development and growth of oats. Pl. Soil. 22: 352-374.

Schwerdtle, F., 1969. (Investigations on the population density of earthworms in relation to conventional tillage and direct drilling.) (German.) Z. PflKrankh. PflSchutz 76: 635-641.

Scott, T. K., 1972. Auxins and roots. A. Rev. Pl. Physiol. 23: 235-258.

Smith, K. A. \& R. S. Russell, 1969. Occurrence of ethylene, and its significance, in anaerobic soil. Nature, Lond. 222: 769-771.

Snow, L. M., 1905. The development of root hairs. Bot. Gaz. 40: 12-48.

Stolzy, L. H. \& K. P. Barley, 1968. Mechanical resistance encountered by roots entering compact soils. Soil Sci. 105: 297-301.

Taylor, H. M. \& H. R. Gardner, 1963. Penetration of cotton seedling tap-roots as influenced by bulk density, moisture content and strength of soil. Soil Sci. 96: 153-156.

Taylor, H. M. \& L. F. Ratliff, 1969. Root elongation rates of cotton and peanuts as a function of soil strength and soil water content. Soil Sci. 108: 113-119.

Trouse, A. C. \& R. P. Humbert, 1961. Some effects of soil compaction on the development of sugar cane roots. Soil Sci. 91: 208-217.

Vaadia, Y. \& C. Itai, 1969. Inter-relationships of growth with reference to the distribution of growth substances. In: W. J. Whittington (Ed.), Root growth, p. 65-79. Butterworths, London.

Weiss, C. \& Y. Vaadia, 1965. Kinetin-like activity in root apices of sunflower plants. Life Sci. 4: $1323-1326$.

Wiersum, L. K., 1957. The relationship of the size and structural rigidity of pores to their penetration by roots. Pl. Soil $9: 75-85$.

Zimmerman, R. P.\& L. T. Kardos, 1961. Effect of bulk density on root growth. Soil Sci. 91: $280-288$. 